\title{
The origin and evolution of the neural crest
}

\author{
Philip C. J. Donoghue ${ }^{1}$, Anthony Graham ${ }^{2}$, and Robert N. Kelsh ${ }^{3}$ \\ ${ }^{1}$ Department of Earth Sciences, University of Bristol, UK \\ ${ }^{2}$ MRC Centre for Developmental Neurobiology, King's College London, UK \\ ${ }^{3}$ Department of Biology and Biochemistry, University of Bath, UK
}

\section{Summary}

Many of the features that distinguish the vertebrates from other chordates are derived from the neural crest, and it has long been argued that the emergence of this multipotent embryonic population was a key innovation underpinning vertebrate evolution. More recently, however, a number of studies have suggested that the evolution of the neural crest was less sudden than previously believed. This has exposed the fact that neural crest, as evidenced by its repertoire of derivative cell types, has evolved through vertebrate evolution. In this light, attempts to derive a typological definition of neural crest, in terms of molecular signatures or networks, are unfounded. We propose a less restrictive, embryological definition of this cell type that facilitates, rather than precludes, investigating the evolution of neural crest. While the evolutionary origin of neural crest has attracted much attention, its subsequent evolution has received almost no attention and yet it is more readily open to experimental investigation and has greater relevance to understanding vertebrate evolution. Finally, we provide a brief outline of how the evolutionary emergence of neural crest potentiality may have proceeded, and how it may be investigated.

\section{Introduction}

The late Peter Thorogood, a much respected Developmental Biologist, told of an instance when, as a new postdoc, he was informed by a senior professor of Zoology that " the only interesting thing about vertebrates was the neural crest". Although at the time this seemed to him to be a bit of hyperbole, Peter began to appreciate that underlying this overstatement there was an important message. Indeed, just a few years later Gans and Northcutt published their hugely influential paper "Neural crest and the origin of vertebrates: a new head" which explicitly made the point that many of the features that distinguish the vertebrates from their nearest relatives have their origin in the neural crest, and that the evolution of the neural crest was central to the evolution of the vertebrates(1). The neural crest was thus seen as being an innovation that appeared coincident with the vertebrates. However, it is now becoming apparent that neural crest cells have a more protracted and gradual evolutionary history and that steps in their emergence can be uncovered. The identification of the stepwise evolution of the neural crest exemplifies an emergent theme in evolutionary developmental biology, which is the attempt to uncover how key features have been assembled during evolution.

Correspondence should be addressed to any one of the authors - e-mail - phil.donoghue@bristol.ac.uk or anthony.graham@kcl.ac.uk orbssrnk@bath.ac.uk.

The authors are listed alphabetically 


\section{The neural crest}

Neural crest cells are a transient embryonic progenitor population that emerges from the dorsal neural tube during early development. The induction of the neural crest begins with an interaction between the epidermal ectoderm and the neural plate to induce the neural plate border. Subsequently, neural crest cells form within the border regions, which rise as neural folds, ultimately converging to form the dorsal midline of the neural tube, and it is from here that the neural crest cells will emerge in an anterior to posterior sequence (Figure 1). These cells migrate into the periphery along stereotypical pathways to a number of sites at which they stop migrating. During and after migration cell differentiate into a very wide range of derivatives that have long been grouped into two categories: ectomesenchymal and non-ectomesenchymal (Figure 2). The ectomesenchymal derivatives include bone, cartilage and dentine. The non-ectomesenchymal derivatives encompass neurons and glia, and diverse pigment cells including melanocytes. There are thus two key features of the neural crest; these cells are migratory and multipotent. A cell type such as this, which can be deployed at a range of sites in the embryo and which can be utilised in a variety of different ways, is clearly a very useful evolutionary innovation and vertebrate evolutionary history is a testament to this potential.

\section{Scenarios for the origin of neural crest}

Inevitably, there has been a long-standing interest in explaining the evolutionary emergence of neural crest. Gans and Northcutt derived hypotheses for the emergence of vertebrate neural crest within a scenario that encompassed development, organismal and ecological evolution, ultimately bringing about the emergence of jawed vertebrates from invertebrate relatives $(1,2)$. However, their scenarios barely touched upon the emergence and evolution of neural crest itself, although they speculated that vertebrate neural crest may have evolved from primary sensory neurons in antecedent invertebrates (2). This scenario was more fully developed by Fritsch and Northcutt who argued more specifically that neural crest evolved from Rohon-Beard cells, a class of primary sensory neurons that occur in the dorsal spinal cord of chordates, projecting axons peripherally onto the lateral migration pathway between the somites and the epidermis that is also used by vertebrate neural crest cells (3). They suggested that dorsal root ganglia evolved from Rohon-Beard cells that had delaminated from the dorsal spinal cord sensory neurons and that subsequently migrated onto the medial pathway(4).

Under the Fritsch-Northcutt scenario, peripheral Rohon-Beard cells would need to dedifferentiate and divide to form the sensory neurons and glia of the dorsal root ganglia and, unfortunately, neurons of the central nervous system are not known to dedifferentiate (hence the paucity of neuron-derived tumours in the central nervous system). Alternatively, their hypothesis could be revived by arguing that the evolutionary developmental origin of neural crest and, more specifically, the sensory neurons and glia of the dorsal root ganglia, is to be found in the migration of mitotically active Rohon-Beard progenitor cells from the dorsal neural tube. There is some experimental evidence in support of this scenario. For instance, it has been shown in zebrafish that Rohon-Beard neurons and neural crest cells form part of an equivalence group (i.e. are alternative derivative cell fates of a common precursor), with Notch/Delta signalling necessary to segregate the two fates $(5,6)$. Furthermore, the transcription factor Prdm1 is required for specification of both RohonBeards and neural crest in zebrafish(7-9). Neural crest cells could thus be considered a subset of Rohon-Beard precursors that delaminate from the nascent spinal cord and migrate into the periphery. 
Scenarios, however, appear to have run their course in attempts to explain the evolutionary origins of vertebrate neural crest. Although experimental support can now be marshalled, it has not been, in part because scenarios have attracted the view that they are untestable (10). More importantly, however, has been the development of molecular methods to characterise or even define neural crest in vertebrates and, subsequently, to divine its origins in invertebrates.

\section{Molecular signatures define neural crest and divine its evolutionary origin}

Classical developmental biology has given way to molecular genetics in the study of neural crest during development and evolution such that, over the last decade, there has been a torrent of experimental evidence concerning the role of various molecular factors in the generation of the neural crest. The induction of neural crest cells has been shown to involve Bmps and Wnts that are expressed in the epidermal ectoderm and which act to promote the formation of premigratory neural crest cells at the edge of the neural plate. Expression of neural crest cell marker genes is preceded by expression of other genes important in neural crest cell induction, including $\mathrm{Zic}, \operatorname{Pax} 3$ and $\operatorname{Pax} 7$ that are expressed more broadly in the neural plate, $m s x 1$ and $m s x 2$, that are expressed in the neural folds and non-neural ectoderm, and Dlx, which is expressed in the non-neural ectoderm only. Together, these factors induce expression of a number of transcription factors including Ap2, cMyc, Foxd3, Id, Slug/Snail, Twist and $\operatorname{Sox} 9$ and $\operatorname{Sox} 10$ in a subset of neural plate border cells to form premigratory neural crest cells. Finally, these cells also express suites of genes involved in the delamination of the neural crest cells, including $r h o B$ and cadherins.

Armed with this information, attempts have been made to identify evolutionary rudiments of neural crest among invertebrates, principally the two clades of invertebrate chordates, the tunicates (e.g. Ciona) and, most especially, the cephalochordates (e.g. Branchiostoma) which, for over a century, have been accepted as the closest living invertebrate relatives of the vertebrates. The main modus operandi has been to examine the expression of one or more 'neural crest genes' during stages of neurulation when neural crest cell delamination occurs in vertebrates(11-13). However, more recently, Bronner-Fraser and colleagues have gone further and, rather than attempting to characterise neural crest by one or more putatively definitive gene, they have attempted to uncover the entire gene regulatory network underpinning neural crest induction, differentiation and migration(14-16). Inevitably, this encompasses more than induction of neural crest alone, and includes all that precedes it, including the induction of the neural plate itself, and all that proceeds it, including the migration and specification of neural crest derivative cell types, leading to an holistic definition of a neural crest cell $(14,15,17)$. Using this definition, they have sought to compare hypothetical gene regulatory networks between vertebrates and invertebrate chordates $(15,16,18,19)$, attempting to find evidence of the evolutionary emergence of neural crest and the assembly of its gene regulatory network.

Collectively, both gene and gene-network surveys for neural crest among invertebrate chordates have demonstrated that $B m p 2 / 4$ is expressed in the non-neural ectoderm, and that Pax3/7, msx 1/2, Zic and slug/snail are expressed at the neural plate border. However, expression of Id, Ets, Twist, SoxE (a member of the SoxE paralogy group to which vertebrate $\operatorname{Sox} 9$ and $\operatorname{Sox} 10$ genes belong) and Fox $D$ (a member of the FoxD paralogy group to which the vertebrate Foxd3 gene belongs), were not found at this position. Indeed, the majority of genes implicated in a neural crest gene regulatory network are expressed in mesodermal, rather than neural plate derivatives(19). These results have been interpreted to indicate that although components of the genetic programme that directs neural crest in development were present in invertebrate chordates, it was not until the emergence of neural crest at the establishment of the vertebrate lineage that the regulatory gene network was 
ultimately established. Thus, an evolutionary rudiment of neural crest cells exists in invertebrate chordates, but it was only after the evolution of the vertebrates that the other key genes required for neural crest production were recruited into this programme(18-21). Thus, it has been concluded that neural crest cells are an exclusively vertebrate characteristic.

\section{Problems with molecular signatures and definitions}

There are, however, limitations to the molecular signature approach, or at least the manner in which it is applied. Firstly, it must be appreciated that the generation of the neural crest occurs within a more general framework that is acting to specify dorsal neural tube fates among chordates, and the neural plate among animals more generally. In vertebrates, the inductive interaction between the epidermal ectoderm and the neural plate results in the formation of the neural folds, which subsequently give rise to neural crest cells and dorsal neural tube cells (Figure 1). Lineage-tracing experiments have shown that even if cells are marked just before migration, labelled progeny can be found in both the neural crest and the dorsal neural tube(22). Thus, the conserved deployment of genes at the interface between the neural plate and the non-neural ectoderm may not indicate the presence of prospective neural crest cells but, rather, dorsal neural tube cells(23). Both cephalochordates and vertebrates display pronounced dorsoventral nerve cord organisation. In both, sensory neurons lie dorsally, while motor neurons are found ventrally. Thus it is probable that the expression of Bmp2/4 in the non-neural ectoderm and Pax 3/7, MsX and Zic genes at the edge of the neural plate rather reflects conservation in the patterning of the nerve cord(13,14,18), rather than latent homologies(11). Overwhelming support for this view comes from the more distant branches of animal phylogeny where, in a study of the formation of the nervous system in annelid embryos, it has been shown that the specification of the neural plate border, involving a common suite of genes, is conserved across Bilateria(24). Thus, in Platynereis dumerilii the non-neural ectoderm expresses Bmp2/4, while the cells at the edge of the neural plate express the Msx, Zic and Pax3/7genes, bounded laterally by $D I x$ expressing cells, just as in vertebrates.

Thus, there are few, if any, definitive neural crest genes that may be used in isolation as molecular signatures of neural crest and so attempts to find an evolutionary rudiment of neural crest among invertebrate chordates, characterised by the expression of a 'neural crest gene' $(11,25)$, were ultimately futile. Instead, all that these studies identified were conserved patterning mechanisms for the mediolateral/ dorsoventral organisation of nervous systems that are general to Bilateria as a whole (Figure 3).

Attempting to use a network definition to explore the evolutionary origin of vertebrate neural crest is also problematic. This occurs in part because no experimentally verified network of transcription factors and their binding sites in target genes expressed in neural crest development has yet been established for any vertebrate, and so no comparative analysis can be undertaken to determine the nature of the neural crest gene regulatory network primitive to vertebrates. Bronner-Fraser and colleagues have made heroic strides towards this ultimate goal, determining the dramatis personae of the neural crest gene regulatory network in Xenopus (14) and lamprey (16), and they have even undertaken comparative analysis of the expression domains of orthologous genes in cephalochordates $(14,19)$.

However, it would be a grave mistake to extend this description of neural crest regulatory development to a molecular definition of neural crest, as some have suggested $(14,15,17)$. Defining neural crest cells in such restrictive, descriptive terms, particularly in ignorance of the core elements of the regulatory network that are both exclusive to neural crest and 
primitive to living vertebrates, precludes any attempt to study the evolutionary origin of neural crest. Furthermore, such an essentialist typological definition is incompatible with incontrovertible evidence that neural crest has evolved. Neural crest cells did not appear pluripotent ex nihilo, but have gradually acquired their better known repertoire of cell fates (26) through vertebrate phylogeny (see below) and evidence from neural plate specification in invertebrates demonstrates that their gene regulatory network is not irreducibly complex. Thus, the characteristics of neural crest exhibited by living vertebrates must have been assembled progressively in members of the vertebrate stem lineage (extinct intermediates of living vertebrates and the last common ancestor they shared with tunicates), or even deeper in chordate phylogeny, after the initial emergence of neural crest (Figure 3).

Indeed, problems may be beginning to emerge with the entire enterprise of defining cell types on the basis of a molecular signature(27), at least in the manner that it is currently practised. For example, Martindale and colleagues have shown that a cohort of genes, orthologues of a regulatory gene network necessary for specification of mesoderm in triploblasts, is expressed in the endoderm of cnidarians - which are classically interpreted to lack mesoderm (28). Similarly, Kosik and colleagues demonstrate that components of a synaptic protein scaffold are present and are co-localised during the development of a sponge and, yet, sponges lack synaptic neurons (29). In these instances, attempts have been made to reinterpet the evidence in two mutually exclusive ways: (i) to reinterpret the anatomy, contradicting classical interpretations and, (ii) to accept classical interpretations and instead to argue that components of the necessary gene regulatory network are in place, and that they represent an evolutionary exaptation (30). However, this serves only to fudge their molecular definition, and we should be alarmed because the cnidarian 'mesoderm' and the 'synaptic neurons' of sponges represent instances where the molecular definition clearly fails, and where phenotypic qualifiers prove critical to identify the presence or absence of characters. Whither attempts to homologise cell types, across the breadth of animal diversity, that would be considered monumentally audacious were it not for our definitive molecular signatures?

\section{Tunicates and the induction of a diagnosis for neural crest}

How might we explore the evolutionary origin of vertebrate neural crest, if not solely on the basis of a molecular signature? It would be erroneous to represent earlier attempts to discover rudimentary neural crest as casting around the embryos of invertebrate chordates looking for any cells expressing 'neural crest genes'. Implicitly or explicitly, these experiments have correctly focussed upon the border of the developing neural plate as the most likely site for discovery (31), and the epithelial-to-mesenchymal transition of neural crest cells as a diagnostic behaviour (32), but even this combination of characters, together with molecular corroboration (31), has not been persuasive because the molecular evidence reflects components of neural plate, rather than specifically neural crest, patterning, and the phenotypic evidence does not distinguish neural crest from neuronal cells more generally. Nevertheless, there must be scope for a phenotypic diagnosis of neural crest or else there would not be the rich history of research into neural crest development, extending beyond the advent of developmental genetics, to the early nineteenth century.

A breakthrough in our perception of neural crest has been afforded by analysis of ascidian tunicates (33) and, in particular of Ecteinascidia turbinata (34). E. turbinata is a colonial ascidian which has a giant tadpole that initiates adult development in its head at a relatively early stage in comparison with other ascidians. The size of this species renders it amenable to cell tracing studies, and it is these that have revealed the presence of 'neural crest-like cells'. Bill Jeffery and colleagues(34) were able to inject small amounts of the lipophilic dye DiI into the neural tube of E. turbinata at different anteroposterior levels and at different 
times. They found that cells could first be seen to be migrating away from the anterior neural tube and then subsequently from the posterior. After leaving the neural tube, these cells populated the siphons and differentiated to form orange pigment cells. The migratory cells of Ecteinascidia can be labelled with the HNK1 antibody, which marks avian neural crest cells, and they have been shown to express a Zic gene. These cells appear similar to vertebrate erythrophores, and genomic analysis in Ciona has identified orthologues of the pteridine synthetic enzymes required for synthesis of xanthophores/erythrophore pigments (35); biochemical and genetic characterisation of these cells to evaluate their true affinity is now a priority.

So are the migratory cells identified in Ecteinascidia neural crest cells? The authors were circumspect in their original description of 'neural crest-like cells'(34), and an air of scepticism has surrounded these data, awaiting evidence of association with molecular factors integral to vertebrate neural crest development(18,36-38). Fundamentally, the answer to this question rests with how neural crest is defined and, as we have seen, a tightly prescribed molecular definition is not appropriate. Instead, what is needed is a more specific but less restrictive diagnosis of what neural crest is, focusing on the fundamental characteristics of neural crest cells.

Regardless of whether we accept the presence of neural crest cells in Ecteinascidia, this evidence forces us to consider the basic characteristics of neural crest. These are elements, also, of the original scenarios that attempted to explain the evolutionary origins of neural crest from Rohon-Beard cells $(2,4)$. In both, it has not been the molecular evidence marshalled, but the principal characters observed or predicted in cell behaviour. These characteristics are:

i. cells that emerge from the neural tube and migrate into the periphery, and

ii. differentiate and generate one or more derivative cell types associated with vertebrate neural crest cells

The neural crest-like cells in Ecteinascidia display these characteristics. The cells migrate from the neural tube in an anterior to posterior sequence, and they populate the periphery where they form orange pigment cells that resemble vertebrate erythrophores, a major neural crest derivative. The generation of other cell types, in particular neurons and glia, from these cells is readily conceivable because these cells are derived from the neural tube (13), though this has yet to be demonstrated. In addition, there are already indications that another type of pigment cell, likely a melanophore, is also found in diverse ascidians and expresses the HNK-1 marker (33), although it remains to be seen whether these are derived by delamination of cells from the CNS and whether they share a precursor with the orange pigment cells. Thus, although some key tests remain, the evidence presented so far indicates that neural crest may well be an innovation of invertebrates, not of vertebrates.

Of course, it remains possible that these delaminating ascidian cells might be an independent evolutionary experiment, simply analogous to vertebrate neural crest (15). After all, there is a general absence of 'neural crest specifier' gene expression from the neural plate border of ascidians. The principle cell phenotype supporting the identification of neural crest-like cells, the orange erythrophore-like pigment cells, is surprising given that they are a derived, not a primitive pigment cell type of vertebrates. Furthermore, tunicates have not, generally, been considered to be the closest invertebrate relatives of the vertebrates - that place has been taken by the cephalochordates which, as we have seen, have yielded no persuasive evidence of the presence of neural crest (11).

These objections are not insurmountable. In regard to the first, it has already been argued that previous studies did not chose the most appropriate stage of development of the most 
appropriate ascidians in which to find evidence of neural crest (39). With reference to the second, there has been no serious undertaking to map out the phylogenetic distribution of neural crest-derivative cell types, so in reality it is not so clear whether erythrophores are more or less ancient than other more familiar neural crest derivatives, such as melanocytes. Finally, the apparent absence of neural crest cells in amphioxus may be due to a secondary loss of these cells(18), or due to the fact that they are to be found at later stages of development(37), which have not as yet been analysed. However, it is also probable that the lack of neural crest cells in cephalochordates is representative of an evolutionary grade more primitive than tunicates and vertebrates. This view, which contradicts several decades of dogma concerning the relationships of the chordates, has recently found favour in molecular phylogenies which seem recently to have become incapable of returning anything other than tunicates, rather than cephalochordates, as the closest living relative of vertebrates(40-44). This would suggest that neural crest cells evolved in the lineage leading to tunicates and vertebrates, the clade Olfactores, after its divergence from the cephalochordate lineage.

Clearly, there is evidence both to support and doubt the identification of bona fide neural crest cells in ascidian tunicates such as Ecteinascidia and key tests of their homology remain to be conducted. Firstly, the multipotency of these cells must be tested. This will require either detailed analysis of cell fates in vivo, to determine whether or not they generate diverse cell types, or an in vitro analysis of their differentiation potential. Demonstration of multiple fates would support homology, but failure would not, unfortunately, lead to a rejection of homology. Secondly, it would be instructive to determine whether orthologues of genes involved in vertebrate pigment cell specification are expressed in the neural crestlike cells of Ecteinascidia, (here the general lack of knowledge of erythrophore genetics will currently be limiting, but this cell-type is closely-related to the xanthophore, so the quest is far from hopeless). A positive result would certainly strengthen the case for an invertebrate neural crest.

In one sense it remains integral that we resolve the case for homology between ascidian neural crest-like cells and vertebrate neural crest. If these cell lineages prove to be historical phylogenetic homologues, it opens a new vista on the origin of a key evolutionary innovation that underpinned the emergence of vertebrates, and the mechanistic basis by which novel cell types - the only accepted metric of evolutionary complexity $(45,46)$ evolve.

In other senses, however, it hardly matters. Firstly, if the neural crest-like cells of Ecteinascidia and its kin prove to be a convergent innovation, we would nevertheless have to infer that such a stage occurred in the evolution of neural crest. Secondly, this entire debate lays bare the fact that there is no such entity as 'vertebrate neural crest'. Neural crest manifests quite a different repertoire of derivative cell types in organisms representative of different evolutionary grades within vertebrate phylogeny (see below). We can come to better understand neural crest evolution, not by plumbing its very origin, but instead by determining the phylogenetic order in which its derivative fates were acquired and, ultimately, determining the manner in which its regulatory gene network has evolved to effect this. Furthermore, investigations of this kind are not hostages to changing perspectives on whether or not tunicates possess an historical phylogenetic homologue of the neural crest encountered in vertebrates.

Given the absence of neural crest derivatives in Amphioxus, and given the wide complement of derivatives in living jawless fishes, it has been possible to say rather little about this in the past. Vertebrate neural crest cells show an impressive range of neuronal fates and, for the moment, the generation of sensory and autonomic neurons and glia from neural crest cells would seem to be a vertebrate apomorphy. Dorsal root ganglia, and an enteric and 
parasympathetic nervous system are present in the most primitive living vertebrates, though a sympathetic nervous system is known from living jawed vertebrates alone(47).

Melanophores are present in hagfishes(48) and lampreys(49), but xanthophores and iridophores have appeared to be an apomorphy of living jawed vertebrates $(50,51)$. Vickaryous and Hall (52) describe 47 neural crest-derived cell phenotypes in humans; precisely when did these novel cell types emerge during vertebrate phylogeny?

\section{The evolutionary emergence of ectomesenchymal potentiality in neural crest}

While it appears that neural crest cells with the ability to generate some nonectomesenchymal derivatives of the neural crest could have evolved prior to the emergence of the vertebrates, the production of ectomesenchymal derivatives is a different, vertebrate, story. There is clear evidence of ectomesenchymal fates in lampreys where cranial and pharyngeal cartilages are known to be of neural crest origin(53,54). Given overwhelming molecular phylogenetic support for the monophyly of hagfishes and lampreys(40,55-57), ectomesenchymal potential of neural crest must be a synapomorphy of living vertebrates at the very least.

Significantly, the fossil record provides evidence for the rapid emergence of other ectomesenchymal fates after the divergence of lampreys and hagfishes from the gnathostome lineage. Stem-gnathostomes, that is, extinct jawless vertebrates that are more closely related to living jawed- that living jawless vertebrates, are largely characterised by their extensive mineralised dermal armour. Although the dermoskeleton shows a sequential acquisition of the characteristics of crown-gnathostomes, from its first manifestation it incorporates dermal teeth composed of enameloid, dentine and dermal bone $(58,59)$, all of which - but especially dentine - are contingent on neural crest for their development in extant vertebrates. Critically, these tissues are present at all axial levels, demanding that trunk, not just cranial neural crest was skeletogenic in these earliest skeletonizing vertebrates(60), a potential that is retained, albeit repressed, in amniotes(61).

\section{Fate specification in development and evolution}

Neural crest has long been the focus of attempts to explain the origin of vertebrates because it is implicated in the development of key phenotypic characters of vertebrates. We suggest that vertebrate evolution may be better understood by examining the evolution of neural crest itself, and developmental studies suggest that this must involve the emergence of novel extrinsic cues coupled with novel responses by the neural crest cells to realise new fates. Indeed, there is already a considerable volume of experimental insight into the most fundamental fate segregation, between ectomesenchymal and non-ectomesenchymal and, as examples, we provide a brief outline how these fates may have been established during vertebrate evolution.

The paths of neural crest cell migration in the trunk are dictated by the somites, and there is a correlation between the migration path and neural crest cell fate. Cells that migrate early move ventrally and are funnelled through the anterior half sclerotome of each somite and form only non-ectomesenchymal derivatives. Many of those cells that migrate furthest ventrally will arrest close to the dorsal aorta and are induced to form the sympathetic ganglia. Cells that arrest more dorsally within the anterior sclerotome generate the sensory neurons and glia of the dorsal root ganglia, due (at least in part) to signals emanating from the neural tube. In contrast, those neural crest cells that migrate late travel laterally between the somite and the ectoderm, giving rise to melanocytes in amniotes, together with other pigment cell-types in anamniotes (amphibians, fish). These same somitic constraints on the 
migratory paths taken by the neural crest are apparent in hagfish embryos(62), indicating that this is a primitive character for vertebrates as a whole.

There is a correlation, too, between the timing of migration of cranial neural crest cells from the developing brain and the fates subsequently acquired by these cells. Early migrating cells fill the pharyngeal arches and assume an ectomesenchymal fate, while late migrating crest cells stay close to the neural tube and generate neurons and glia. However, there is no difference in potential between the early- and late-migrating cranial crest cells, hence, if late-migrating crest cells are substituted for early-migrating cells, they will fill the pharyngeal arches and make a substantial contribution to skeletal elements(63). Thus, it would seem that the allocation of neural crest cells to an ectomesenchymal fate must involve environmental cues within the arches.

One such cue has been shown to be FGF signalling. Pharyngeal epithelia express FGFs and neural crest cells express FGF receptors. If neural crest cells are rendered insensitive to FGF signalling they will enter the pharyngeal arches as normal, but they will not assume an ectomesenchymal fate, instead persisting in the expression of early neural crest markers(64). Indeed, FGF signalling plays an ongoing role in the development of ectomesenchymal derivatives. FGFs act to promote the proliferation and survival of the ectomesemchymal crest $(65,66)$, and are required for differentiation. Absence of FGF function results in a failure in the formation of pharyngeal cartilages $(67,68)$, and the culturing of neural crest cells in FGFs promotes skeletogenesis $(69,70)$. However, it is likely that FGFs on their own are not enough to direct neural crest cells to ectomesenchymal fates and that other signalling molecules expressed by the epithelia are also required (64).

In addition to these extrinsic cues, neural crest cell multipotency requires intrinsic factors, especially cellular receptors, and transcription factors that help mediate the transcriptional changes that underlie fate specification(71). It is clear, therefore, that underlying the cellular property of multipotency must be a molecular signature of diverse receptors. The tour de force gene regulatory analyses of Eric Davidson's group on sea urchins have become influential in describing gene regulatory networks that form the core of the developmental genetic circuitry for individual cell-types(72,73). In this light, the acquisition of novel fates can, in many cases, be seen as simply requiring the co-option by neural crest cells of gene regulatory modules used in the central nervous system and other tissues $(14,16)$. The attainment of new cell fate potential presumably requires the acquisition of new specification factor receptors and/or their 'wiring' into the regulatory circuitry driving new fates.

The SoxE subfamily of transcription factors are intrinsic factors that are likely to have played a significant role in establishing ectomesenchymal crest during early vertebrate evolution. Sox 9 function lies at the core of chondrocyte specification $(74,75)$, and in all Sox 10 mutants, ectomesenchymal derivatives develop but there is a failure in the formation of all non-ectomesenchymal derivatives(76). This evidence suggests that, although there is evidence of considerable redundancy among SoxE genes (Sox8, Sox 9, Sox 10) in neural crest development(77-80), there is a distinct developmental programme that directs neural crest cells to become ectomesenchymal, and this must have evolved through subfunctionalization within the vertebrates. The SoxE group itself is as ancient as animals(81), but its diversification into the three recognised paralogues evidently occurred in stem-vertebrates; Branchiostoma and Ciona possess a single, preduplication SoxE gene $(14,20)$, while lampreys possess Sox8 and Sox9 orthologues(82). Expression of SoxE in Branchiostoma is not associated with neural plate development(14) while the known SoxE genes in lampreys are associated with the development of ectomesenchymal neural crest derivatives $(82,83)$. This suggests that SoxE genes were co-opted to the neural plate, and that 
they had a primitive role in neural crest development prior to their diversification in stemvertebrates.

However, novel fate potential may emerge by more conservative means. One relatively straight-forward mechanism by which this might be achieved is in cell-fates that, whilst being novelties for the neural crest, are already part of the cellular repertoire of the organism. The melanocyte provides an effective example. Melanised cells are found in the central nervous system of invertebrate chordates, for example in the otoliths and ocelli of ascidians, and they are retained in vertebrates in the form of the pigmented retinal epithelium. In the case of both melanocytes, ascidian otoliths and ocelli(25) and the vertebrate pigmented retinal epithelium, melanogenesis is dependent upon a key transcription factor, Mitf(84-89). In zebrafish and mice Wnt signalling is an important inducer of Mitf transcription in the neural crest(90-92). Thus, it is likely that core elements of the gene regulatory network for melanogenesis in vertebrates exist in invertebrate chordates, integrated into CNS development so as to generate melanised cells in the CNS. Co-option of this melanogenic subroutine would require the incorporation of the Wnt growth factor/receptor signalling pathway into the regulatory circuitry of Mitf, rather than derivation of the entire network from scratch. A transcriptional component of this core melanogenesis circuitry would seem to be Pax $3 / 7$ since Mitf regulation in mammals depends upon Pax3 $(93,94)$ and since Pax3/7 in ascidians can drive ectopic melanin(89).

How do these more specific novel cell fates emerge in development and evolution? By direct development from undifferentiated neural crest cells, through the modification of existing differentiation pathways, or by transdifferentiation? We have presented evidence of fate segregation between ectomesenchymal and non-ectomesenchymal fates, and perhaps neuroglial versus pigment cell fates, indicating that at least at this level, there is evidence for cell fate novelty arising in evolution through the adaptation of existing pathways. Cladistic analysis of the characteristics of cell types bears out the expectation of nested similarity (Figure 4) (52), and this may serve as a predictive framework for investigating the regulatory gene network underpinning neural crest cell differentiation, which is already envisaged to follow multitiered hierarchical lineage segregation(95). At present there is little evidence for an hierarchical gene regulatory network underpinning alternative cell fates and evidence that many cell fates undergo transdifferentiation $(96,97)$, has been exploited to argue that novel cell types evolved by transdifferentiation $(52,98)$. However, this line of reasoning serves only to commit the classic error of conflating a developmental process with an evolutionary pattern(99), and it is likely that this view will be rescinded by an evolutionary perspective on accumulating experimental evidence on molecular basis of lineage segregation, fate determination and dedifferentiation $(95,100)$.

\section{Conclusion}

Neural crest is both more and less than the sum of its gene regulatory network. There is no typological definition of neural crest to be captured. All of the evidence available to us indicates that neural crest is an evolving entity and, as such, the best that can be achieved is a diagnosis: a population of cells that emerges from the neural tube and migrates to the periphery where it differentiates and generates one or more characteristic derivative cell types. The inventory of derivative cell types has increased throughout vertebrate evolution, but many have also been lost in specific lineages, such as iridophores and xanthophores in amniotes. Thus, ascidian 'neural crest-like cells' fulfil expectations of an early grade of neural crest evolution. Insights into the evolutionary emergence of neural crest potentiality will always prove challenging because even the earliest branching vertebrate lineages with extant representatives manifest the main classes of neural crest derivatives. However, there is much more to neural crest evolution than its very origin. The repertoire of neural crest 
derivatives has expanded throughout vertebrate evolution (e.g. pigment, skeletal and particularly neuronal cell types) and the molecular and developmental basis of their evolutionary origins is a tractable subject that may provide insights into the events surrounding the early evolution of neural crest.

Previously, the majority of research on the evolution of the vertebrates has been focussed on the understanding the origin of major anatomical novelties such as a differentiated nervous system, jaws and a skeleton. The evolution of the neural crest, aside from diving its origin, has attracted precious little attention. However, as we have shown here, it represents the major challenge and an excellent opportunity for future research.

\section{Acknowledgments}

We thank Kevin Peterson (Dartmouth) and the colleagues in his laboratory for their comments on an earlier draft of this manuscript. The authors would also like thank the following bodies for funding the work in their labs- P.C.J.D. is funded by The National Endowment for Science, Technology and the Arts, and The Leverhulme Trust, A.G. is funded by the Wellcome Trust, R. N. K. is funded by the Wellcome Trust, MRC (UK), and the BBSRC.

\section{References}

1. Gans C, Northcutt RG. Neural crest and the origin of the vertebrates: a new head. Science. 1983; 220:268-274. [PubMed: 17732898]

2. Northcutt RG, Gans C. The genesis of neural crest and epidermal placodes: a reinterpretation of vertebrate origins. Quarterly Review of Biology. 1983; 58:1-28. [PubMed: 6346380]

3. Bernhardt RR, Chitnis AB, Lindamer L, Kuwada JY. Identification of spinal neurons in the embryonic and larval zebrafish. Journal of Comparative Neurology. 1990; 302:603-616. [PubMed: 1702120]

4. Fritzsch B, Northcutt RG. Cranial and spinal nerve organization in Amphioxus and lampreys: evidence for an ancestral craniate pattern. Acta Anatomica. 1993; 148:96-109. [PubMed: 8109201]

5. Cornell RA, Eisen JS. Delta signaling mediates segregation of neural crest and spinal sensory neurons from zebrafish lateral neural plate. Development. 2000; 127:2873-2882. [PubMed: 10851132]

6. Cornell RA, Eisen JS. Delta/Notch signaling promotes formation of zebrafish neural crest by repressing Neurogenin 1 function. Development. 2002; 129:2639-2648. [PubMed: 12015292]

7. Hernandez-Lagunas L, Choi IF, Kaji T, Simpson P, Hershey C, Zhou Y, Zon L, Mercola M, Artinger KB. Zebrafish narrowminded disrupts the transcription factor prdm1 and is required for neural crest and sensory neuron specification. Developmental Biology. 2005; 278:347-357. [PubMed: 15680355]

8. Roy S, Ng T. Blimp-1 specifies neural crest and sensory neuron progenitors in the zebrafish embryo. Current Biology. 2004; 14:1772-1777. [PubMed: 15458650]

9. Artinger KB, Chitnis AB, Mercola M, Driever W. Zebrafish narrowminded suggests a genetic link between formation of neural crest and primary sensory neurons. Development. 1999; 126:3969_ 3979. [PubMed: 10457007]

10. Purnell MA. Feeding in extinct jawless heterostracan fishes and testing scenarios of early vertebrate evolution. Proceedings of the Royal Society of London, Series B. 2002; 269:83-88. [PubMed: 11788040]

11. Stone JR, Hall BK. Latent homologues for the neural crest as an evolutionary novelty. Evolution \& Development. 2004; 6:123-129. [PubMed: 15009125]

12. Benito-Gutiérrez È . A gene catalogue of the amphioxus nervous system. International Journal of Biological Sciences. 2006; 2:149-169. [PubMed: 16763675]

13. Pasini A, Amiel A, Rothb, cher U, Roure A, Lemaire P, Darras Sébastien. Formation of the ascidian epidermal sensory neurons: insights into the origin of the chordate peripheral nervous system. PLoS Biology. 2006; 4:e225. [PubMed: 16787106] 
14. Meulemans D, Bronner-Fraser M. Gene-regulatory interactions in neural crest evolution and development. Developmental Cell. 2004; 7:291-299. [PubMed: 15363405]

15. Sauka-Spengler T, Bronner-Fraser M. Development and evolution of the migratory neural crest: a gene regulatory perspective. Current Opinion in Genetics \& Development. 2006; 16:360-366. [PubMed: 16793256]

16. Sauka-Spengler T, Meulemans D, Jones M, Bronner-Fraser M. Ancient evolutionary origin of the neural crest gene regulatory network. Developmental Cell. 2007; 13:405-420. [PubMed: 17765683]

17. Raible DW. Development of the neural crest: achieving specificity in regulatory pathways. Current Opinion in Cell Biology. 2006; 18:698-703. [PubMed: 17030122]

18. Meulemans D, Bronner-Fraser M. Central role of gene cooption in neural crest evolution. Journal of Experimental Zoology Part B-Molecular and Developmental Evolution. 2005; 304B:298-303. [PubMed: 15880502]

19. Meulemans D, Bronner-Fraser M. Insights from Amphioxus into the evolution of vertebrate cartilage. PLoS ONE. 2007; 2:e787. [PubMed: 17726517]

20. Wada H, Makabe K. Genome duplications of early vertebrates as a possible chronicle of the evolutionary history of the neural crest. International Journal of Biological Sciences. 2006; 2:133141. [PubMed: 16763673]

21. Martinez-Morales JR, Henrich T, Ramialison M, Wittbrodt J. New genes in the evolution of the neural crest differentiation program. Genome Biology. 2007; 8

22. Selleck MAJ, Bronner-Fraser M. Origins of the avian neural crest: the role of neural plateepidermal interactions. Development. 1995; 121:525-538. [PubMed: 7768190]

23. Shimeld SM, Holland PWH. Vertebrate innovations. Proceedings of the National Academy of Sciences, USA. 2000; 97:4449-4452.

24. Denes AS, Jekely G, Steinmetz PRH, Raible F, Snyman H, Prud'homme B, Ferrier DEK, Balavoine G, Arendt D. Molecular architecture of annelid nerve cord supports common origin of nervous system centralization in Bilateria. Cell. 2007; 129:277-288. [PubMed: 17448990]

25. Wada H. Origin and evolution of the neural crest: A hypothetical reconstruction of its evolutionary history. Development Growth \& Differentiation. 2001; 43:509-520.

26. Hall, BK. The neural crest in development and evolution. Springer-Verlag; New York: 1999. p. 313

27. Arendt D. Genes and homology in nervous system evolution: Comparing gene functions, expression patterns, and cell type molecular fingerprints. Theory in Biosciences. 2005; 124:185197. [PubMed: 17046355]

28. Martindale MQ, Pang K, Finnerty JR. Investigating the origins of triploblasty: 'mesodermal' gene expression in a diploblastic animal, the sea anemone Nematostella vectensis (phylum, Cnidaria; class, Anthozoa). Development. 2004; 131:2463-2474. [PubMed: 15128674]

29. Sakarya O, Armstrong KA, Adamska M, Adamski M, Wang IF, Tidor B, Degnan BM, Oakley TH, Kosik KS. A post-synaptic scaffold at the origin of the animal kingdom. PLoS ONE. 2007; 2:e506. [PubMed: 17551586]

30. Gould SJ, Vrba ES. Exaptation - a missing term in the science of form. Paleobiology. 1982; 8:415.

31. Holland ND, Panganiban G, Henyey EL, Holland LZ. Sequence and developmental expression of AmphiDIl, an amphioxus Distal-less gene transcribed ion the ectoderm, epidermis and nervous system: insights into evolution of craniate forebrain and neural crest. Development. 1996; 122:2911-2920. [PubMed: 8787764]

32. Baker CVH, Bronner-Fraser M. The origins of the neural crest. Part II: an evolutionary perspective. Mechanisms of Development. 1997; 69:13-29. [PubMed: 9486528]

33. Jeffery WR. Ascidian neural crest-like cells: Phylogenetic distribution, relationship to larval complexity, and pigment cell fate. Journal of Experimental Zoology Part B-Molecular and Developmental Evolution. 2006; 306B:470-480. [PubMed: 16619245]

34. Jeffery WR, Strickler AG, Yamamoto Y. Migratory neural crest-like cells form body pigment in a urochordate embryo. Nature. 2004; 431:696-699. [PubMed: 15470430] 
35. Takeuchi K, Satoul Y, Yamamoto H, Satoh N. A genome-wide survey of genes for enzymes involved in pigment synthesis in an ascidian, Ciona intestinalis. Zoological Science. 2005; 22:723-734. [PubMed: 16082161]

36. Northcutt RG. The new head hypothesis revisited. Journal of Experimental Zoology Part BMolecular and Developmental Evolution. 2005; 304B:274-297.

37. Baker CVH, Schlosser G. The evolutionary origin of neural crest and plaeodes. Journal of Experimental Zoology Part B-Molecular and Developmental Evolution. 2005; 304B:269-273. [PubMed: 16003767]

38. Barrallo-Gimeno, A.; Nieto, MA. Evolution of the neural crest. In: Saint-Jeannet, J-P., editor. Neural crest induction and differentiation. Springer; 2005. p. 235-244.

39. Jeffery WR. Chordate ancestry of the neural crest: New insights from ascidians. Seminars in Cell \& Developmental Biology. 2007; 18:481-491. [PubMed: 17509911]

40. Delsuc F, Brinkmann H, Chourrout D, Philippe H. Tunicates and not cephalochordates are the closest living relatives of vertebrates. Nature. 2006; 439:965-968. [PubMed: 16495997]

41. Philippe H, Lartillot N, Brinkmann H. Multigene Analyses of Bilaterian Animals Corroborate the Monophyly of Ecdysozoa, Lophotrochozoa, and Protostomia. Mol Biol Evol. 2005; 22:12461253. [PubMed: 15703236]

42. Blair JE, Hedges SB. Molecular phylogeny and divergence times of deuterostome animals. Mol Biol Evol. 2005; 22:2275-2284. [PubMed: 16049193]

43. Bourlat SJ, Juliusdottir T, Lowe CJ, Freeman R, Aronowicz J, Kirschner M, Lander ES, Thorndyke M, Nakano H, Kohn AB. Deuterostome phylogeny reveals monophyletic chordates and the new phylum Xenoturbellida. Nature. 2006; 444:85-88. others. [PubMed: 17051155]

44. Vienne A, Pontarotti P. Metaphylogeny of 82 gene families sheds a new light on chordate evolution. International Journal of Biological Sciences. 2006; 2:32-37. [PubMed: 16733531]

45. Valentine JW, Collins AG, Meyer CP. Morphological complexity increase in metazoans. Paleobiology. 1994; 20:131-142.

46. Vogel C, Chothia C. Protein family expansions and biological complexity. Plos Computational Biology. 2006; 2:370-382.

47. Hirata M, Ito K, Tsuneki K. Migration and colonization patterns of HNK-1 -immunoreactive neural crest cells in lamprey and swordtail embryos. Zoological Science. 1997; 14:305-312.

48. Coonfield BR. The pigment in the skin of Myxine glutinosa Linn. Transactions of the American Microscopical Society. 1940; 59:398-403.

49. Steven DM. Sensory cells and pigment distribution in the tail of the Ammocoete. Quarterly Journal of Microscopical Science. 1951; 92:233-247.

50. Mellgren EM, Johnson SL. The evolution of morphological complexity in zebrafish stripes. Trends in Genetics. 2002; 18:128-134. [PubMed: 11858836]

51. Hadley ME. Functional significance of vertebrate integumental pigmentation. American Zoologist. 1972; 12:63-76.

52. Vickaryous MK, Hall BK. Human cell type diversity, evolution, development, and classification with special reference to cells derived from the neural crest. Biological Reviews. 2006; 81:425455. [PubMed: 16790079]

53. Langille RM, Hall BK. Role of neural crest in development of the trabeculae and branchial arches in embryonic sea lamprey, Petromyzon marinus (L). Development. 1988; 102:301-310.

54. McCauley DW, Bronner-Fraser M. Neural crest contributions to the lamprey head. Development. 2003; 130:2317-2327. [PubMed: 12702647]

55. Delarbre C, Barriel V, Janvier P, Gachelin G. Complete Mitochondrial DNA of the Hagfish, Eptatretus burgeri: The Comparative Analysis of Mitochondrial DNA Sequences Strongly Supports the Cyclostome Monophyly. Molecular Phylogenetics and Evolution. 2002; 22:184-192. [PubMed: 11820840]

56. Furlong RF, Holland PWH. Bayesian phylogenetic analysis supports monophyly of Ambulacraria and of cyclostomes. Zoological Science. 2002; 19:593-599. [PubMed: 12130812] 
57. Mallatt J, Winchell CJ. Ribosomal RNA genes and deuterostome phylogeny revisited: More cyclostomes, elasmobranchs, reptiles, and a brittle star. Molecular Phylogenetics and Evolution. 2007; 43:1005-1022. [PubMed: 17276090]

58. Sansom IJ, Donoghue PCJ, Albanesi GL. Histology and affinity of the earliest armoured vertebrate. Biology Letters. 2005; 2:446-449. [PubMed: 17148229]

59. Donoghue PCJ, Sansom IJ, Downs JP. Early evolution of vertebrate skeletal tissues and cellular interactions, and the canalization of skeletal development. Journal of Experimental Zoology - Part B: Molecular and Developmental Evolution. 2006; 306B:278-294. [PubMed: 16555304]

60. Smith MM, Hall BK. Development and evolutionary origins of vertebrate skeletogenic and odontogenic tissues. Biological Reviews. 1990; 65:277-373. [PubMed: 2205303]

61. McGonnell IM, Graham A. Trunk neural crest has skeletogenic potential. Current Biology. 2002; 12:767-771. [PubMed: 12007423]

62. Ota KG, Kuraku S, Kuratani S. Hagfish embryology with reference to the evolution of the neural crest. Nature. 2007; 446:672-675. [PubMed: 17377535]

63. Baker CV, Bronner-Fraser M, Le Douarin NM, Teillet MA. Early- and late-migrating cranial neural crest cell populations have equivalent developmental potential in vivo. Development. 1997; 124:3077-3087. [PubMed: 9272949]

64. Blentic A, Tandon P, Payton S, Walshe J, Carney T, Kelsh RN, Mason I, Graham A. The emergence of ectomesenchyme. Developmental Dynamics. 2008 in press.

65. Trumpp A, Depew MJ, Rubenstein JL, Bishop JM, Martin GR. Cre-mediated gene inactivation demonstrates that FGF8 is required for cell survival and patterning of the first branchial arch. Genes Dev. 1999; 13:3136-3148. [PubMed: 10601039]

66. Creuzet S, Schuler B, Couly G, Le Douarin NM. Reciprocal relationships between Fgf8 and neural crest cells in facial and forebrain development. Proc Natl Acad Sci U S A. 2004; 101:4843-4847. [PubMed: 15041748]

67. David NB, Saint-Etienne L, Tsang M, Schilling TF, Rosa FM. Requirement for endoderm and FGF3 in ventral head skeleton formation. Development. 2002; 129:4457-4468. [PubMed: 12223404]

68. Walshe J, Mason I. Fgf signalling is required for formation of cartilage in the head. Dev Biol. 2003; 264:522-536. [PubMed: 14651935]

69. Sarkar S, Petiot A, Copp A, Ferretti P, Thorogood P. FGF2 promotes skeletogenic differentiation of cranial neural crest cells. Development. 2001; 128:2143-2152. [PubMed: 11493535]

70. Ido A, Ito K. Expression of chondrogenic potential of mouse trunk neural crest cells by FGF2 treatment. Dev Dyn. 2006; 235:361-367. [PubMed: 16273527]

71. Kelsh RN. Sorting out Sox10 functions in neural crest development. BioEssays. 2006; 28:788-798. [PubMed: 16927299]

72. Davidson EH, Rast JP, Oliveri P, Ransick A, Calestani C, Yuh CH, Minokawa T, Amore G, Hinman V, Arenas-Mena C. A genomic regulatory network for development. Science. 2002; 295:1669-1678. others. [PubMed: 11872831]

73. Davidson, EH. The regulatory genome: gene regulatory networks in development and evolution. Academic Press; San Diego: 2006. p. 261

74. Bi WM, Deng JM, Zhang ZP, Behringer RR, de Crombrugghe B. Sox9 is required for cartilage formation. Nature Genetics. 1999; 22:85-89. [PubMed: 10319868]

75. Yan Y-L, Miller CT, Nissen RM, Singer A, Liu D, Kirn A, Draper B, Willoughby J, Morcos PA, Amsterdam A. A zebrafish sox 9 gene required for cartilage morphogenesis. Development. 2002; 129:5065-5079. others. [PubMed: 12397114]

76. Dutton KA, Pauliny A, Lopes SS, Elworthy S, Carney TJ, Rauch J, Geisler R, Haffter P, Kelsh RN. Zebrafish colourless encodes sox10 and specifies non- ectomesenchymal neural crest fates. Development. 2001; 128:4113-4125. [PubMed: 11684650]

77. Taylor KM, LaBonne C. SoxE factors function equivalently during neural crest and inner ear development and their activity is regulated by SUMOylation. Developmental Cell. 2005; 9:593603. [PubMed: 16256735]

78. Hong CS, Saint-Jeannet JP. Sox proteins and neural crest development. Seminars in Cell \& Developmental Biology. 2005; 16:694-703. [PubMed: 16039883] 
79. Stolt CC, Lommes P, Friedrich RP, Wegner M. Transcription factors Sox 8 and Sox 10 perform non-equivalent roles during oligodendrocyte development despite functional redundancy. Development. 2004; 131:2349-2358. [PubMed: 15102707]

80. Carney TJ, Dutton KA, Greenhill E, Delfino-Machin M, Dufourcq P, Blader P, Kelsh RN. A direct role for Sox 10 in specification of neural crest-derived sensory neurons. Development. 2006; 133:4619-4630. [PubMed: 17065232]

81. Larroux C, Fahey B, Liubicich D, Hinman VF, Gauthier M, Gongora M, Green K, Worheide G, Leys SP, Degnan BM. Developmental expression of transcription factor genes in a demosponge: insights into the origin of metazoan multicellularity. Evolution \& Development. 2006; 8:150-173. [PubMed: 16509894]

82. Zhang G, Miyamoto MM, Cohn MJ. Lamprey type II collagen and Sox9 reveal an ancient origin of the vertebrate collagenous skeleton. PNAS. 2006; 103:3180-3185. [PubMed: 16492784]

83. McCauley DW, Bronner-Fraser M. Importance of SoxE in neural crest development and the evolution of the pharynx. Nature. 2006; 441:750-752. [PubMed: 16760978]

84. Kumasaka M, Sato S, Yajima I, Goding CR, Yamamoto H. Regulation of melanoblast and retinal pigment epithelium development by Xenopus laevis Mitf. Developmental Dynamics. 2005; 234:523-534. [PubMed: 16028277]

85. Lister JA, Robertson CP, Lepage T, Johnson SL, Raible DW. nacre encodes a zebrafish microphthalmia-related protein that regulates neural-crest-derived pigment cell fate. Development. 1999; 126:3757-3767. [PubMed: 10433906]

86. Tachibana M, Takeda K, Nobukuni Y, Urabe K. Ectopic expression of MITF, a gene for Waardenburg syndrome type 2, converts fibroblasts to cells with melanocyte characteristics. Nature Genetics. 1996; 14:50-54. [PubMed: 8782819]

87. Steingrimsson E, Moore KJ, Lamoreux ML, Ferredamare AR, Burley SK, Zimring DCS, Skow LC, Hodgkinson CA, Arnheiter H, Copeland NG. Molecular-Basis of Mouse Microphthalmia (Mi) Mutations Helps Explain Their Developmental and Phenotypic Consequences. Nature Genetics. 1994; 8:256-263. others. [PubMed: 7874168]

88. Tachibana M, Perezjurado LA, Nakayama A, Hodgkinson CA, Li X, Schneider M, Miki T, Fex J, Francke U, Arnheiter H. Cloning of Mitf, the Human Homolog of the Mouse Microphthalmia Gene and Assignment to Chromosome 3p14.1 - P12.3. Human Molecular Genetics. 1994; 3:553557. [PubMed: 8069297]

89. Yajima L, Endo K, Sato S, Toyoda R, Wada H, Shibahara S, Numakunai T, Ikeo K, Gojobori T, Goding CR. Cloning and functional analysis of ascidian Mitf in vivo: insights into the origin of vertebrate pigment cells. Mechanisms of Development. 2003; 120:1489-1504. others. [PubMed: 14654221]

90. Yasumoto K, Takeda K, Saito H, Watanabe K, Takahashi K, Shibahara S. Microphthalmiaassociated transcription factor interacts with LEF-1, a mediator of Wnt signaling. Embo Journal. 2002; 21:2703-2714. [PubMed: 12032083]

91. Takeda K, Yasumoto K, Takada R, Takada S, Watanabe K, Udono T, Saito H, Takahashi K, Shibahara S. Induction of melanocyte-specific microphthalmia-associated transcription factor by Wnt-3a. Journal of Biological Chemistry. 2000; 275:14013-14016. [PubMed: 10747853]

92. Dorsky RI, Raible DW, Moon RT. Direct regulation of nacre, a zebrafish MITF homolog required for pigment cell formation, by the Wnt pathway. Genes \& Development. 2000; 14:158-162. [PubMed: 10652270]

93. Bondurand N, Pingault V, Goerich DE, Lemort N, Sock E, Le Caignec C, Wegner M, Goossens M. Interaction among SOX10 PAX3 and MITF, three genes altered in Waardenburg syndrome. Human Molecular Genetics. 2000; 9:1907-1917. [PubMed: 10942418]

94. Potterf SB, Furumura M, Dunn KJ, Arnheiter H, Pavan WJ. Transcription factor hierarchy in Waardenburg syndrome: regulation of MITF expression by SOX10 and PAX3. Human Genetics. 2000; 107:1-6. [PubMed: 10982026]

95. Dupin E, Calloni G, Real C, Goncalves-Trentin A, Le Douarin NM. Neural crest progenitors and stem cells. Comptes Rendus Biologies. 2007; 330:521-529. [PubMed: 17631447]

96. Aubin JE, Liu F, Malaval L, Gupta AK. Osteoblast and chondroblast differentiation. Bone. 1995; 17:S77-S83. 
97. Hall, BK. Bones and cartilage: developmental skeletal biology. Elsevier; 2005. p. 792

98. Eisenberg LM, Eisenberg CA. Stem cell plasticity, cell fusion, and transdifferentiation. Birth Defects Research Part C: Embryo Today: Reviews. 2003; 69:209-218.

99. Donoghue PCJ. Evolution of development of vertebrate teeth and scales: unravelling concepts, regulatory theories and homologies. Paleobiology. 2002; 28:474-507.

100. Delfino-MachÌn M, Chipperfield TR, Rodrigues FSLM, Kelsh RN. The proliferating field of neural crest stem cells. Developmental Dynamics. 2007; 236:3242-3254. [PubMed: 17823935] 
a

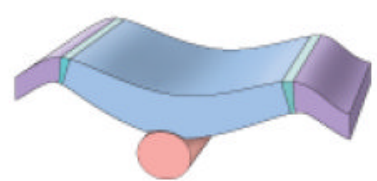

b

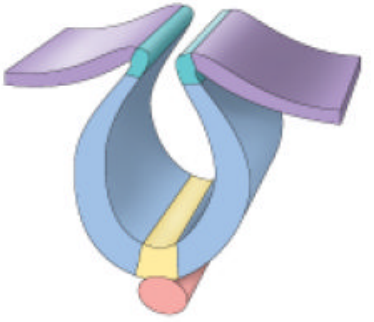

c

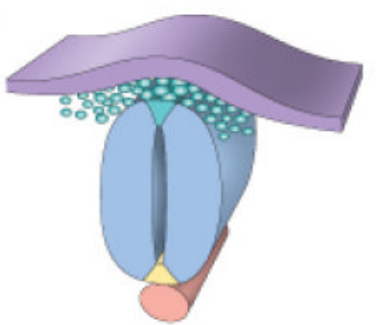

Figure 1.

The principal derivative cell types of neural crest.

The major derivatives of neural crest cells are schematically illustrated here, grouped according to whether they are classified as ectomesenchymal or non-ectomesenchymal. 


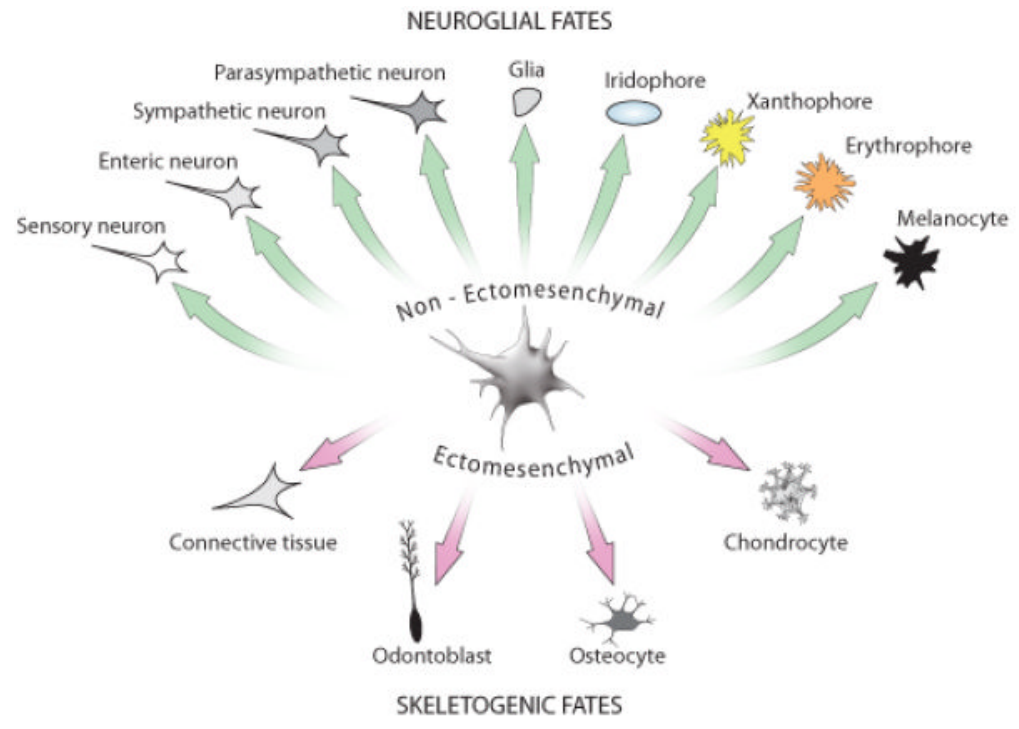

Figure 2.

Stages in the formation of the neural crest.

A) At the neural plate stage the non-neural ectoderm signals to the neural plate, primarily through the actions of Bmp's and wnt's, to specify the neural plate border region. The notochord underlies the midline of the neural plate. B) As neurulation progresses, the neural plate infolds and the neural plate border rises up and forms the neural folds. At the ventral midline of the neural plate, the floor plate is induced to form by the notochord. The floor plate and notochord will act to pattern the ventral neural tube. C) Following apposition of the neural folds and their fusion across the midline, the neural tube is forms. The neural crest cells emigrate from the dorsal most region of the neural tube, which is derived from the neural folds. This dorsal territory will also generate the roof plate, and this structure will act to pattern the dorsal neural tube. 


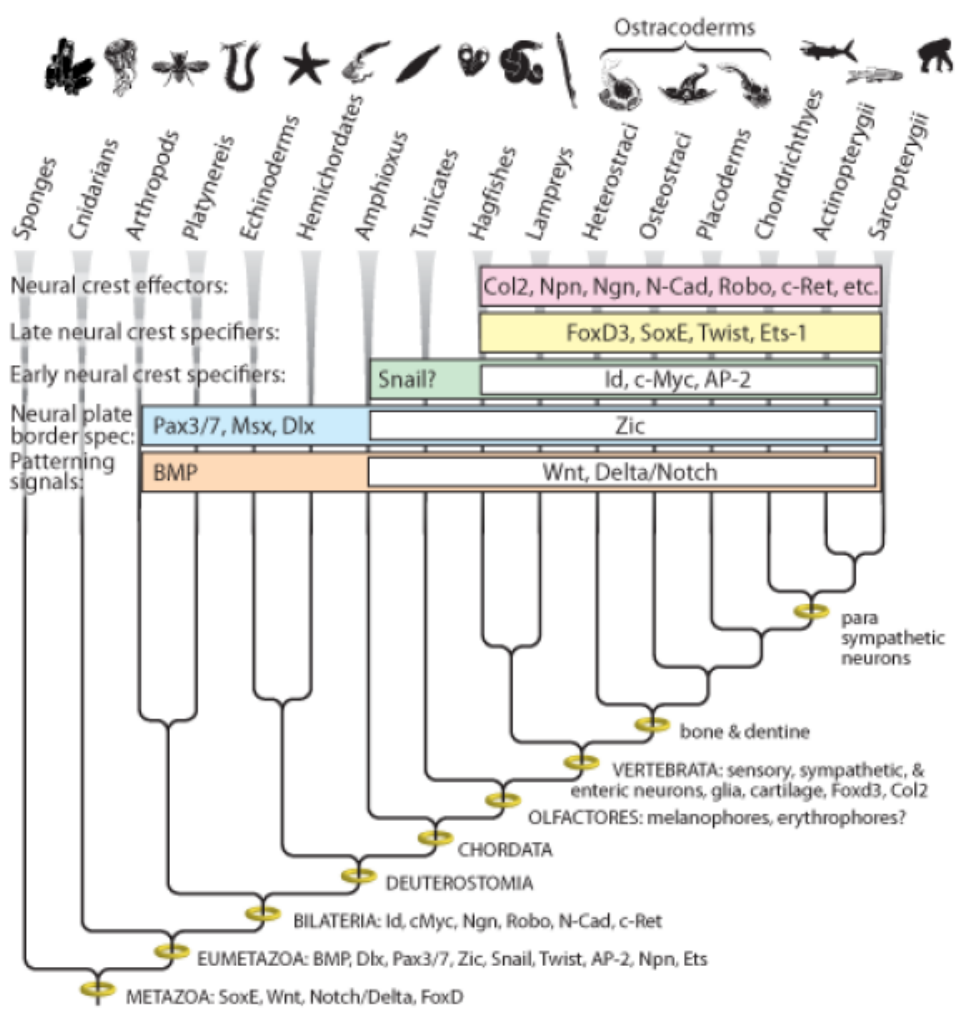

Figure 3.

The evolutionary assembly of the neural crest gene regulatory network (GRN). Across the tips of the tree we have indicated by the extent of the box, enveloping more or less branches, the evolutionary addition of the various elements of the neural crest GRN as identified by Sauka-Spengler and colleagues(16). This clearly shows that although functional integration of neural crest specifiers and effectors into the GRN occurs only in vertebrates, the early patterning and neural plate border specification network components have a much more protracted evolutionary history, extending at least to the last common ancestor of triploblastic bilaterian eumetazoans. The integration of the key signalling molecules and transcription factors into the neural crest GRN should not, however, be confused with the evolutionary origin of these factors, the majority of which were present in the last common ancestor of metazoans, as indicated by their point of origin in the internal branches of the tree. Finally, the apparent point of evolutionary origin of major neural crest cell phenotypes is also indicated on the internal branches of the tree. 


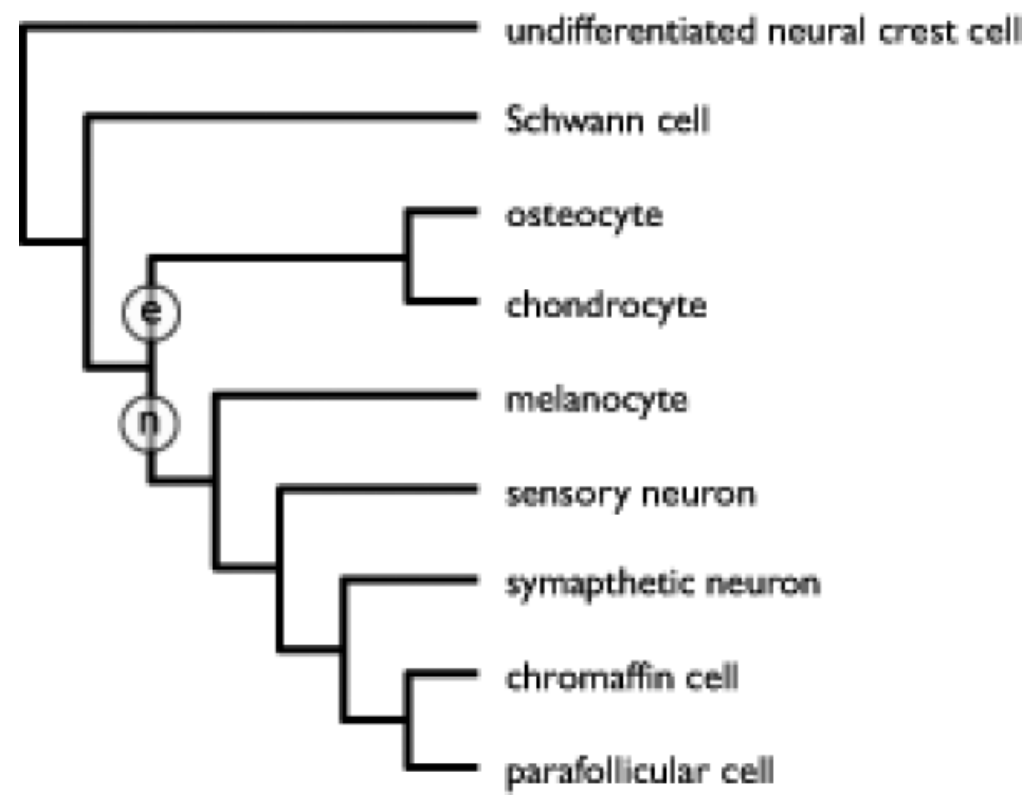

Figure 4.

Hierarchical relationships between principal categories of neural crest cell-type derivatives based on a cladistic analysis of their characteristics, undertaken by Vickaryous and Hall(52). The analysis is based on a character matrix that encompasses aspects of cell phenotype, behaviour and labelling, and was subjected to both phenetic cluster analysis and cladistic parsimony analysis; only the results of the parsimony analysis are presented here. The hierarchy bears out the dichotomy between ectomesenchymal (e) and non-ectomesenchymal (n) fates. 
Table 1

Some key neural crest-related genes

\begin{tabular}{|c|c|c|c|c|}
\hline Gene & Encodes a... & Expressed in... & During... & Function \\
\hline Bmp & Growth factor & Non-neural ectoderm & Gastrulation & Neural crest induction \\
\hline Wnt & Growth factor & Non-neural ectoderm & Gastrulation & Neural crest induction \\
\hline $\mathrm{Zic}$ & Transcription factor & Neural folds \& neural plate & Neurula & Neural plate border specifier \\
\hline $\operatorname{Pax} 3 / 7$ & Transcription factor & Neural folds \& neural plate & Neurula & Neural plate border specifier \\
\hline Msx $1 / 2$ & ??transcription factor & Neural folds \& non-neural ectoderm & Neurula & Neural plate border specifier \\
\hline Dlx & Transcription factor & Neural folds and non-neural ectoderm & Neurula & Neural plate border specifier \\
\hline Ap2 & Transcription factor & Premigratory neural crest & Segmentation & Neural crest specifier \\
\hline cMyc & Transcription factor & Premigratory neural crest & Segmentation & Neural crest specifier \\
\hline FoxD3 & Transcription factor & Premigratory neural crest & Segmentation & Neural crest specifier \\
\hline Id & Transcription factor & Premigratory neural crest & Segmentation & Neural crest specifier \\
\hline Twist & Transcription factor & Premigratory neural crest & Segmentation & Neural crest specifier \\
\hline Sox 9 & Transcription factor & Premigratory neural crest & Segmentation & Neural crest specifier \\
\hline Sox 10 & Transcription factor & Premigratory neural crest & Segmentation & Neural crest specifier \\
\hline Slug/snail & Transcription factor & Premigratory neural crest & Segmentation & Regulates neural crest cell delamination \\
\hline RhoB & Rho GTPase & Premigratory neural crest & Segmentation & Neural crest cell delamination \\
\hline Cadherin & Cell adhesion molecule & Ectodermal epithelia & Segmentation & $\begin{array}{l}\text { Changes in cadherins promote neural crest } \\
\text { delamination }\end{array}$ \\
\hline
\end{tabular}

